\title{
The association between Lymphogranuloma venereum and HIV among men who have sex with men: systematic review and meta-analysis
}

\author{
Minttu M Rönn*, Helen Ward
}

\begin{abstract}
Background: Lymphogranuloma venereum (LGV) is an important re-emerging sexually transmitted infection which is reported to affect particularly HIV-positive men who have sex with men (MSM). The aim of this study is to quantify the association between LGV and HIV in the context of the current emergence of LGV.

Methods: A systematic review was performed on the emergence of LGV among MSM since 2000. We report the prevalence of HIV infection from descriptive studies of MSM with LGV, and conduct a meta-analysis to produce a summary estimate of the association between LGV and HIV from case-control studies where cases were MSM with LGV and controls were MSM with rectal chlamydia caused by non-LGV serovars.

Results: The prevalence of HIV among LGV cases ranges from $67 \%$ to $100 \%$ in 13 descriptive studies. There is a significant association between HIV and LGV (odds ratio 8.19, 95\% Cl 4.68-14.33).

Conclusions: HIV-positive MSM are disproportionately affected by LGV highlighting the importance of prevention efforts to be targeted to this group. Further research is needed to determine whether the association is due to biological or behavioural factors.
\end{abstract}

\section{Background}

Lymphogranuloma venereum (LGV) is a sexually transmitted infection (STI) which largely disappeared from the Western world after the introduction of antibiotics. LGV is caused by the species Chlamydia trachomatis (CT) which produces infection in humans and includes three biovars [1]; serovars A-C cause trachoma, an eye infection that mainly spreads via child-to-child transmission and is the leading cause of preventable blindness, while the second biovar (serovars D-K, and occasionally also $B$ [2]) is transmitted sexually [3]. Serovars A-K have a limited host-cell range, they infect mainly squamocolumnar epithelial cells and are incapable of infecting deeper tissues. The third biovar, LGV, is formed by serovars L1, L2 and L3 and it causes a more invasive disease due to its ability to infect macrophages and consequently it can spread to lymphatic tissue at the site of infection leading to a systemic disease [4]. LGV is

\footnotetext{
* Correspondence: minttu.ronn08@imperial.ac.uk
Department of Infectious Disease Epidemiology, Imperial College London,

* Correspondence: minttu.ronn08@imperial.ac.uk
Department of Infectious Disease Epidemiology, Imperial College London, Old Medical School, St. Mary's Campus, Norfolk Place, Paddington, W2 IPG London, UK
}

(c) 2011 Rönn and Ward; licensee BioMed Central Ltd. This is an Open Access article distributed under the terms of the Creative Commons Attribution License (http://creativecommons.org/licenses/by/2.0), which permits unrestricted use, distribution, and reproduction in any medium, provided the original work is properly cited. tissue tropism for mucosa contrary to non-LGV chlamy dia, and it has been considered endemic in the tropics although LGV epidemiology in these areas has not been systematically described. In 2003 a cluster of LGV cases was reported in Rotterdam, the Netherlands [5] and, following an international alert, case reports were published of similar outbreaks in large European cities [6-10]. Reports of LGV from the United States [11], Canada [12] and Australia [13] followed.

The clinical features of LGV have historically been divided into three stages: the primary stage involves the site of inoculation where a small papule, ulcer, herpetiform lesion or nonspecific urethritis appears after incubation period of 3-30 days [4]. During the secondary stage, which emerges after 10-30 days or even months later, local lymph nodes draining the site of primary infection enlarge and necrotic areas develop following an inflammatory process which results in chronic oedema and formation of ulcers and sclerosing fibrosis. Without adequate treatment a tertiary phase with chronic inflammatory response will follow. This is 
characterized by genital ulcers, fistulas, rectal strictures and genital elephantiasis. The scarring and formation of fibrotic tissue often requires surgical repair [4]. The classical manifestation in men is characterised by inguinal lymphadenopathy. During the recent emergence of LGV, the clinical manifestation has been different. Acute ulcerative proctitis or proctocolitis is often seen as the primary manifestation $[4,14]$ (approximately 96\% of the cases in the United Kingdom [15]) while inguinal lymphadenopathy alone has been observed in only a few cases [16]. Rectal discharge, pain, bleeding [14] and systemic symptoms such as malaise [17] and high white blood cell count ( $>10 /$ high power field) in gram stained rectal smears [18] have been reported as indicators of LGV. It is not clear why inguinal symptoms, indicating urethral acquisition of LGV, have been so rare and it has been suggested that different modes of transmission, such as sexual practices of fisting and use of sex toys and other fomites, are contributing to the spread of LGV. Traumatic practices to the mucosa have been previously associated with the acquisition of other rare STIs such as sexually acquired hepatitis $C$ virus [19].

In response to the outbreak surveillance systems were established in several affected countries. These have produced a consistent picture of cases among men who have sex with men (MSM), many of whom are coinfected with HIV (for example $74 \%$ co-infection rates in the UK [20] and over 70\% reported in other European countries [21]). On average, affected patients have also been older (mean age above 35 [21]) than MSM presenting to STI clinics for other reasons, and with a high rate of concurrent STIs and hepatitis C (14\% of cases in the UK [20]). In 2009 a case-finding study in genitourinary medicine (GUM) clinics in London found a prevalence estimate of LGV among MSM to be $1.2 \%$ (36 out of 3076 men) [22] while another case-finding exercise conducted in four GUM clinics in London and Brighton found LGV positivity among rectal samples from MSM to be $0.9 \%$ (61 of 6778 rectal samples tested for LGV) [23].

As LGV seems to be circulating mainly among HIVpositive MSM it is important to consider the effect these STIs have on each other [24]. STIs may contribute to transmission of HIV and concurrent HIV infection may alter the epidemiology of an STI: both STI and HIV can become more infectious in a co-infected individual. HIV may also increase the susceptibility of an HIV-positive individual to other STIs and HIV may be transmitted more easily in discordant couple if the HIVnegative partner has a concurrent STI [25]. In meta-analysis by Rottingen et al. (2001) [25] both GUD and CT were found to increase susceptibility to HIV-infection in heterosexual transmission and it would seem plausible that LGV may increase HIV transmission also in homosexual partnerships. The aim of this study is to quantify the association between HIV infection and LGV among MSM in the context of the current emergence of LGV.

\section{Methods}

\section{Search strategy}

A systematic review was conducted using PubMed of the National Center for Biotechnology Information (NCBI), MEDLINE of the National Library of Medicine (NLM) and Web of Science (the latter two via ISI Web of Knowledge platform). The search was restricted for the years 2000-2009. The searches were performed on 17 June 2009 using the search words "Lymphogranuloma venereum" (MeSH, and topic search) and the acronym LGV with Boolean search looking for any of the words. No restrictions were selected on the type of studies, or publication language. An additional search was done in Eurosurveillance [26] on 18 June 2009 using the advanced search and selecting "Lymphogranuloma venereum - LGV" from the subject list. The article search focused on covering all scientific publications of LGV after 2000, as case-finding and reporting of the emergence of LGV has started after 2003. Novel diagnostic methods have been developed recently [27] and this has enhanced the reliability of LGV diagnosis.

The grey literature was searched online using the websites of national public health agencies and professional organisations including the Health Protection Agency of England and Wales, the British Association for Sexual Health and HIV, the Public Health Agency of Canada and the Centres for Disease Prevention and Control of the United States. Reference lists of LGV publications were utilised to identify relevant literature and they were also reviewed for completeness of already found publications. No attempt was made to identify unpublished studies. Ethical approval was not sought, since the study relied on published data only.

\section{Study selection}

The study selection was done in two stages: during the first phase all publications involving a component of LGV epidemiology or management of LGV were included apart from publications focusing on the molecular biology of LGV or CT which were excluded. The study selection at this point was done based on abstract or the full publication if abstract did not give sufficient information. At the second phase complete publications were reviewed and their suitability in respect to the research objective was assessed. Studies were included if they met the following criteria: the main outcome was LGV and the study population was composed of MSM with data available for the level of HIV co-infection among study subjects. The selection of papers was 
restricted to MSM as they have been most affected by LGV in developed countries, and because the clinical manifestation of LGV is different among homosexuals than heterosexuals. Case-series and conference abstracts were excluded at the second stage of the review.

\section{Data extraction}

From the descriptive studies that met all the inclusion criteria, the following variables were obtained: first author, year of publication, purpose and type of the study, study period, sample size, number of confirmed LGV cases (confirmation of LGV status requires detection of L1-L3 serovars from a chlamydia positive sample), age as reported in the paper, number of HIV positive LGV cases as well as number of cases with negative or unknown HIV status. Additionally from case-control studies information on the effect sizes and their confidence intervals and two by two table of the distribution of HIV serostatus was retrieved. When several publications reported data from the same setting, the latest or most complete report was used. The eligible publications were in English and Swedish as the first author is fluent in both languages.

\section{Analytic methods}

To estimate the prevalence of HIV among LGV cases, raw pooled prevalence estimates were calculated based on the numbers of HIV-positive and negative individuals given in the publications. A summary estimate was constructed and heterogeneity of the estimates explored using meta-analysis (using inverse-variance and derSimonian and Laird method [28]). To calculate variance estimates, studies were excluded if the number of expected cases was less than 5 in order to avoid skewed summary estimates. In order to make the distribution nearer to normal meta-analysis was run using logits (log of the odds) of the prevalence estimates and final results transformed back to prevalence [29].

To analyse LGV-HIV association in case-control studies, a meta-analysis was performed using MantelHaenszel fixed-effect method as presented by Petitti (2000) [30]. For tests of heterogeneity chi-square test was used and also random-effect method (derSimonianLaird method) which yields close to identical results to fixed-effect method in the absence of heterogeneity. Statistical analyses were done using STATA10. Reporting followed the guidance of PRISMA statement (preferred reporting items for systematic reviews and meta-analyses) [31].

\section{Results}

\section{Details of included and excluded articles}

The search produced the following results: PubMed 270, Medline 273 and Web of Science 264. Many citations were common to all three search engines and after removal of duplicates there was a total of 368 original publications for the years 2000 to 2009. Eurosurveillance had 21 publications under the subject heading Lymphogranuloma venereum out of which 3 were identified through Eurosurveillance search only $[5,8,10]$. Searching the grey literature gave 4 additional LGV-related results [32-35] and a search of the reference lists gave six more publications [36-41] that fulfilled the primary inclusion criteria.

During the first stage of the review 140 publications were excluded (Figure 1). Full copies of 241 articles were reviewed in the second stage of the review. The systematic review identified 23 potentially relevant articles from which data extraction was performed and after excluding 6 publications with overlapping study period $[15,17,42-45] 17$ publications remained that fulfilled the inclusion criteria

\section{Estimating level of HIV co-infection among LGV-cases}

The review identified 13 cross-sectional or descriptive studies that provided information on the prevalence of HIV among LGV cases. The majority were surveillance reports of LGV cases, and characteristics are presented in Additional file 1, Table S1. A total of 1145 confirmed LGV cases were reported by the studies, of which 985 had epidemiological data ( $86.3 \%$ of cases). Among the confirmed cases there was a high level of HIV co-infection, ranging from $67 \%$ to $100 \%$ across the reports. The raw pooled prevalence estimate was $77.9 \%$ (95\% CI 75.0$80.8 \%$ ) among cases with known HIV status. However, there was a significant amount of missing data on HIV status, with $19.8 \%$ of cases having unknown status. To statistically explore heterogeneity, a meta-analysis for the prevalence estimates was performed using the known HIV statuses from the publications. This was done for five studies with expected number of cases of five or more [20,46-49] (the eligible publications are highlighted in table S1). A fixed-effect model gave a summary estimate of $74.5 \%$ and random-effect model $78.2 \%$ (raw pooled estimate of the included five studies $76.3 \%)$. The test for heterogeneity among these studies was statistically significant (p-value $<0.001$ ) and thus a summary estimate was deemed an inappropriate approach and should be used for illustrative purposes only due to the underlying differences between studies.

\section{Estimating the association between LGV and HIV}

Four case-control studies were indentified that estimated the association between LGV and HIV (Additional file 1, Table S2). In these studies all the cases have LGV proctitis and included a control group with non-LGV CT (some studies had more than one control group). A summary OR for the HIV-positives was calculated using 


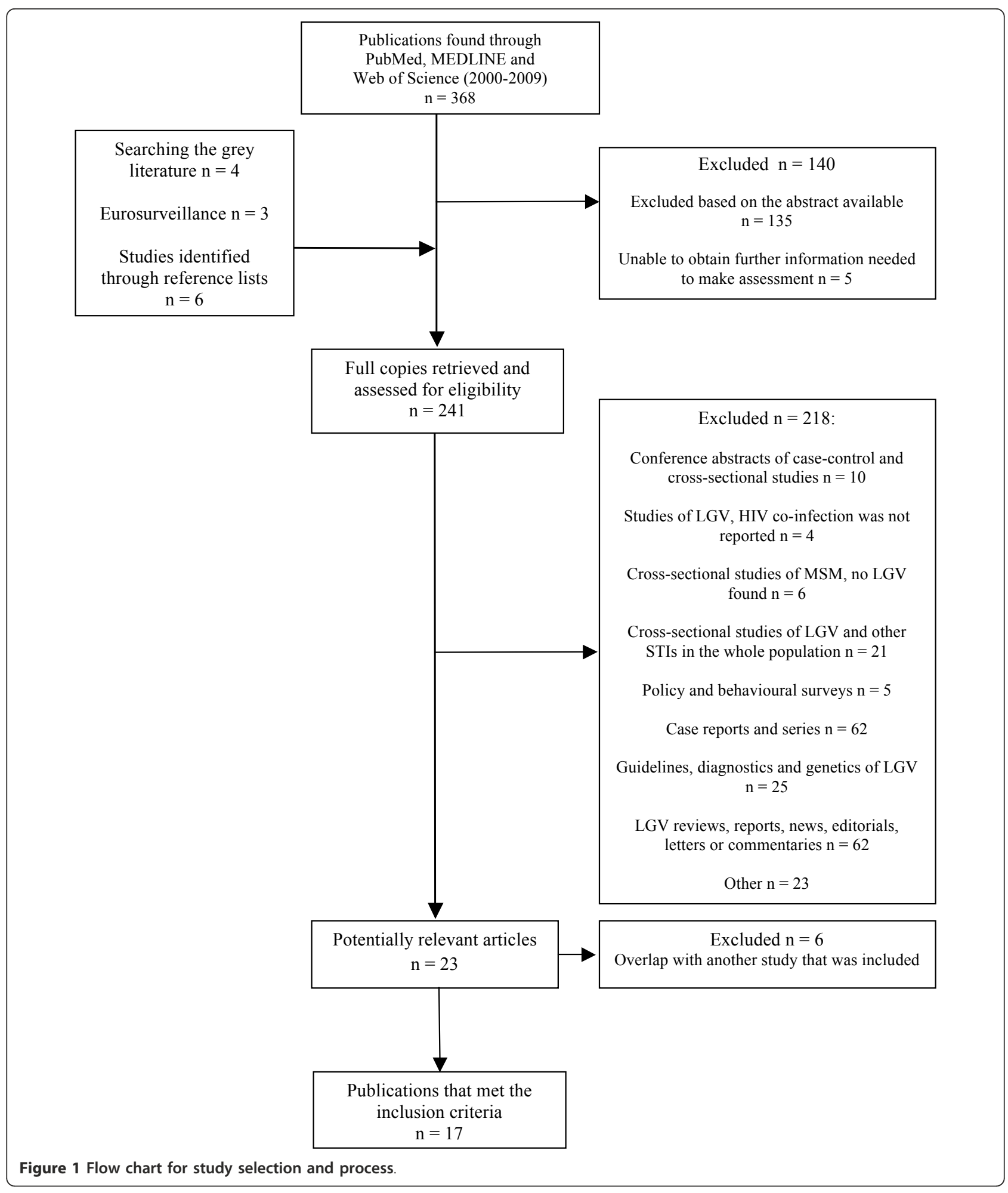

HIV-seronegative patients as a reference group, and the resulting forest plot is presented in Figure 2. The summary estimate demonstrates that MSM with LGV are eight times more likely to have HIV (OR 8.19, 95\% CI 4.68-14.33, p-value < 0.001) compared to MSM with
non-LGV CT. The statistical test for heterogeneity did not show a significant difference between the study groups (p-value 0.519). Study by van der Bij has the largest weight as it has over twice as many cases and controls compared to other studies. Due to the small 


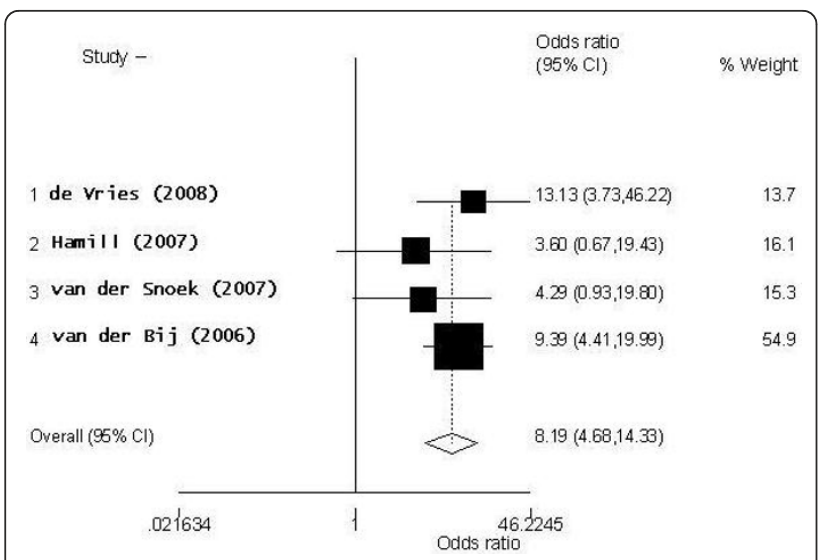

Figure 2 Forest plot of HIV-LGV association using fixed-effect model.

number of people with an unknown HIV-serostatus (only van der Bij had a large number of participants with unknown status), the association between that and LGV was not explored.

As a random-effect model produced very similar results to a fixed-effect model, further statistical tests for heterogeneity were not conducted. Sources of heterogeneity were explored by looking into potential differences in the study design. There seems to have been few methodological differences between the studies: all the study participants were recruited on STI clinics based on their sexual risk-behaviour or symptoms reported. All the LGV cases were confirmed using either real-time PCR of RFLP-PCR as were non-LGV CT controls. It is unlikely that there are significant differences between the study populations as three of the studies were conducted in the Netherlands (two in Amsterdam and one in Rotterdam) and one study in London, UK. Therefore it seems that no large methodological, clinical or geographic sources of heterogeneity can be detected between the studies.

\section{Discussion}

We found consistent evidence of a strong association between HIV and LGV across the literature. In thirteen descriptive studies at least two-thirds of MSM with LGV were co-infected with HIV. In a meta-analysis, MSM with LGV were over eight times more likely to have HIV (OR 8.19, 95\% CI 4.68-14.33) than those who had non-LGV chlamydia infection. This association is stronger than for other sexually transmitted infections which have also re-emerged in MSM over the past decade [50]. As the descriptive studies presented results mainly in aggregate form, it was not possible to further investigate the effect of LGV genotype or rectal and non-rectal infection on the association between HIV and LGV. However, in the majority of studies rectal symptoms and proctitis were the dominant manifestation of LGV, as shown by results from the three largest studies: in the UK $90 \%$ of confirmed cases had proctitis [20], in France only rectal swabs were included in the surveillance system [47], and $91 \%$ of cases in Netherlands had proctitis [49]. Similarly only aggregate information was available for LGV genotype, but Canada [12], France [47] and the Netherlands [46] found only L2b genotype in the samples that were sequenced. Other descriptive studies selected for this study found mainly L2 serotype with predominantly L2b variant in the sequenced samples (such as $426 / 470$ of samples in UK surveillance that were confirmed L2b [20]). Primary data sources would be needed to analyse differences between HIV positive and HIV negative LGV cases.

A number of detailed reviews have been published on the emergence of LGV $[14,51]$. However to our knowledge this review is the first to systematically identify and quantitatively analyse the association between HIV and LGV in the re-emergence of LGV, and includes data from 17 reports. However, it is limited by the inclusion of a number of surveillance reports. Surveillance of LGV is said to suffer from the lack of consistency between countries giving rise to different case-definitions and surveillance methods, some of which are based on voluntary and potentially partial reporting [52]. Surveillance reports formed a large proportion of publications used for the HIV-prevalence estimates, but the studies in this review all defined detection of LGV serovars as a requirement for confirmed cases. Nevertheless it is possible that cases have been identified with different accuracy between countries and the international data may not be comparable. Previous literature has noted that the variation in the structure of surveillance systems limits cross-country comparison [53]. The geographical differences may be a result of variation in sexual partnerships, differential sexual behaviours (such as seroadaptive behaviour), testing and case finding policies, time of introduction of LGV into the network and the impact of local public health interventions [50].

In this review we did not apply strict quality criteria. This is due to the relatively small number of published studies and our desire to be inclusive in order to increase sample size. This means that we cannot exclude the possibility that sampling and measurement differences may account for some of the heterogeneity. Outcome-level assessment for LGV was performed by including only confirmed cases (identification of LGV serovars required for a confirmed case) which assures the validity of the data for the main outcome. Due to the small number of studies conducted to date and the recent emergence of LGV, publication bias was not thought to be relevant in this analysis. The search and article retrieval was conducted by the first author alone, 
but the analysis and interpretation was done by both authors.

The strong association between LGV and HIV in an unadjusted model is interesting, and some association would be expected to remain after adjusting for confounders, especially since the association is strong even though the control group represents another high risk group of MSM with a non-LGV CT infection. It is possible that there may be a biological interaction between HIV-infection and LGV. HIV-infection has been reported to cause abnormalities in the structure and function of the gastrointestinal tract as well as abnormal lymphocyte trafficking [54] that may facilitate LGV acquisition. In a South African cohort of patients with GUD, LGV infection was diagnosed more often among the HIV-infected participants compared to HIV-negative participants with relative risk 1.3 (95\% CI 1.2-1.4) [55]. Also in the Bahamas, an LGV epidemic was associated with crack cocaine use and HIV infection [56]. Two of the case-control studies included in this review compared median CD4 count between cases and controls, but neither found a significant difference $[57,58]$. van der Bij et al. [18] also hypothesised that immunorestoration inflammatory syndrome could explain the emergence of this highly symptomatic LGV. They analysed the association between having symptomatic LGV and start of highly active antiretroviral therapy (HAART) but no association was found. Time-series analysis may be a more effective way to measure the potential interaction between HIV and LGV.

The strongest confounder for this hypothesis is highrisk sexual behaviour. There have been behavioural changes in MSM communities as a response to HIV epidemic, and serosorting may make HIV-positivity an intermediating factor: individuals participate in certain type of practices partly because of their HIV-infection [59]. Seroadaptive behaviour can reduce the number of new HIV infections but it also facilitates the spread of other STIs and can create dense sexual networks where disease propagation is fast [53]. Exploring this further was not possible in this review because of the lack of comparable data on sexual behaviour.

\section{Conclusions}

The findings from HIV prevalence estimates and casecontrol studies reveal that HIV-infected MSM are disproportionately affected by the emergence of LGV. LGV prevention efforts should be targeted towards HIVinfected sexually active MSM. Although the majority of LGV infected individuals are HIV-positive, a proportion of diagnosed LGV cases are HIV-negative and this group would benefit from primary HIV prevention as they belong to sexual networks where HIV-seropositivity is common and subsequently they are at high risk of HIV-infection.
The strong association between LGV and HIV coinfection identified from case control studies may indicate a biological synergy between LGV and HIV, but further research is required to explore the relationship between HIV-infection, behaviour and acquisition of LGV.

\section{Additional material}

Additional file 1: Table S1 and Table S2. Table S1 presents the descriptive studies selected for the analysis of prevalence of HIV coinfection in LGV cases, and Table S2 presents the case-control studies with estimates of association between HIV-positivity and LGV [60-67].

\section{Acknowledgements}

We would like to thank the following people for their contribution to this study: Dr Henry J. C. de Vries offered his insight into previous case-control studies. Dr Gabriela Gomez and Dr Gopalakrishnan Netuveli gave advice on statistical analysis. We would also like to thank the reviewers for helpful suggestions to strengthen our manuscript.

Financial support. MRC grant (G0601699)

\section{Authors' contributions}

HW and MR defined the research questions. MR performed the review and conducted the analysis and HW reviewed the results. Both authors wrote or reviewed the article. Both authors read and approved the final manuscript.

\section{Competing interests}

The authors declare that they have no competing interests.

Received: 7 July 2010 Accepted: 18 March 2011

Published: 18 March 2011

\section{References}

1. Thomson NR, Holden MTG, Carder C, Lennard N, Lockey SJ, Marsh P, Skipp P, O'Connor CD, Goodhead I, Norbertzcak H, et al: Chlamydia trachomatis: genome sequence analysis of lymphogranuloma venereum isolates. Genome Research 2008, 18(1):161-171.

2. Schachter J, Stephens RS: Biology of Chlamydia trachomatis. In Sexually Transmitted Diseases. 4 edition. Edited by: Holmes KK, Sparling PF, Stamm WE, Piot P, Wasserheit JN, Corey L, Cohen MS, Watts C. The McGraw-Hill Companies; 2008:555-574.

3. Pannekoek Y, Morelli G, Kusecek B, Morre SA, Ossewaarde JM, Langerak AA, van der Ende A: Multi locus sequence typing of Chlamydiales: clonal groupings within the obligate intracellular bacteria Chlamydia trachomatis. BMC Microbiol 2008, 8:42.

4. Stamm WE: Lymphogranuloma venereum. In Sexually Transmitted Diseases. 4 edition. Edited by: Holmes KK, Sparling PF, Stamm WE, Piot P, Wasserheit JN, Corey L, Cohen MS, Watts DH. The McGraw-Hill Companies; 2008:595-605.

5. Götz H, Nieuwenhuis R, Ossewaarde T, Bing Thio H, van der Meijden W, Dees J, de Zwart O: Preliminary report of an outbreak of lymphogranuloma venereum in homosexual men in the Netherlands, with implications for other countries in western Europe. Euro Surveill 2004, 8(4)

6. Liassine N, Caulfield A, Ory G, Restellini A, de Barbeyrac B, Sitavanc R, Descombes MC, Luescher D: First confirmed case of lymphogranuloma venereum (LGV) in Switzerland. Euro Surveill 2005, 10(7), E050714.050714.

7. Berglund T, Bratt G, Herrmann B, Karlsson A, Lofdahl M, Payne L: Two cases of lymphogranuloma venereum (LGV) in homosexual men in Stockholm. Euro Surveill 2005, 10(3), E050303.050303.

8. Plettenberg A, von Krosigk A, Stoehr A, Meyer T: Four cases of lymphogranuloma venereum in Hamburg, 2003. Euro Surveill 2004, 8(30).

9. Vall Mayans M, Sanz Colomo B, Ossewaarde JM: First case of LGV confirmed in Barcelona. Euro Surveill 2005, 10(2), E050203.050202. 
10. von Holsterin I, Fenton AF, Ison C: European network for surveillance of STIs (ESSTI) establishes working groups on lymphogranuloma venereum and HIV/STI prevention among MSM. Euro Surveill 2004, 8(25).

11. Ahdoot A, Kotler DP, Suh JS, Kutler C, Flamholz R: Lymphogranuloma venereum in human immunodeficiency virus-infected individuals in New York City. J Clin Gastroenterol 2006, 40(5):385-390.

12. Kropp RY, Wong T, Canadian LGWWG: Emergence of lymphogranuloma venereum in Canada. CMAJ 2005, 172(13):1674-1676.

13. Morton AN, Fairley CK, Zaia AM, Chen MY: Anorectal lymphogranuloma venereum in a Melbourne man. Sex Health 2006, 3(3):189-190.

14. White J: Manifestations and management of lymphogranuloma venereum. Curr Opin Infect Dis 2009, , 22: 57-66.

15. Ward H, Martin I, Macdonald N, Alexander S, Simms I, Fenton K, French P, Dean G, Ison C: Lymphogranuloma venereum in the United kingdom. Clin infect Dis 2007, 44(1):26-32.

16. Sethi G, Allason-Jones E, Richens J, Annan NT, Hawkins D, Ekbote A Alexander $S$, White J: Lymphogranuloma venereum presenting as genital ulceration and inguinal syndrome in men who have sex with men in London, United Kingdom. Sex Transm Inf 2008, 85(3):165-170.

17. Macdonald N, Ison C, Martin I, Alexander S, Lowndes C, Simms I, Ward H: Initial results of enhanced surveillance for lymphogranuloma venereum (LGV) in England. Euro Surveill 2005, 10(1), E050127.050125.

18. Van der Bij AK, Spargaren J, Morre SA, Fennema HS, Mindel A, Coutinho RA, de Vries HJ: Diagnostic and clinical implications of anorectal lymphogranuloma venereum in men who have sex with men: a retrospective case-control study. Clin Infect Dis 2006, 42(2):186-194.

19. Danta M, Brown D, Bhagani S, Pybus OG, Sabin CA, Nelson M, Fisher M, Johnson AM, Dusheiko GM, Hiv, et al: Recent epidemic of acute hepatitis $\mathrm{C}$ virus in HIV-positive men who have sex with men linked to high-risk sexual behaviours. AIDS (London, England) 2007, 21(8):983-991.

20. Jebbari H, Alexander S, Ward H, Evans B, Solomou M, Thornton A, Dean G, White J, French $\mathrm{P}$, Ison $\mathrm{C}$, et al: Update on lymphogranuloma venereum in the United Kingdom. Sex Transm Inf 2007, 83(4):324-326.

21. van de Laar MJW: The emergence of LGV in western Europe: what do we know, what can we do? Euro Surveill 2006, 11(9):146-148.

22. Annan NT, Sullivan AK, Nori A, Naydenova P, Alexander S, McKenna A Azadian B, Mandalia S, Rossi M, Ward H, et al: Rectal chlamydia-a reservoir of undiagnosed infection in men who have sex with men. Sex Transm Inf 2009, 85(3):176-179.

23. Ward H, Alexander S, Carder C, Dean G, French P, Ivens D, Ling C, Paul J, Tong W, White J, et al: The prevalence of lymphogranuloma venereum infection in men who have sex with men: results of a multicentre case finding study. Sex Transm Inf 2009, 85(3):173-175.

24. Ward $H$, Rönn M: Contribution of sexually transmitted infections to the sexual transmission of HIV. Curr Opin HIV AIDS 2010, 5(4):305-310.

25. Rottingen JA, Cameron DW, Garnett GP: A systematic review of the epidemiologic interactions between classic sexually transmitted diseases and HIV: how much really is known? Sex Transm Dis 2001, 28(10):579-597.

26. Eurosurveillance. [http://www.eurosurveillance.org/Default.aspx]

27. Morre SA, Ouburg S, van Agtmael MA, de Vries HJ: Lymphogranuloma venereum diagnostics: from culture to real-time quadriplex polymerase chain reaction. Sex Transm Inf 2008, 84(4):252-253.

28. Egger M, Davey Smith G, Altman DG: Systematic reviews in health care: meta-analysis in context. London: BMJ Publishing Group; 2001.

29. Kirkwood BR, Sterne JAC: Essential Medical Statistics. Oxford: Balckwell Science, 22008.

30. Petitti DP: Meta-Analysis, Decision Analysis, and Cost-Effectiveness Analysis, Methods for Quantitative Synthesis in Medicine. New York: Oxford University Press; 2000.

31. Moher D, Liberati A, Tetzlaff J, Altman DG, Group P: Preferred reporting items for systematic reviews and meta-analyses: the PRISMA statement. BMJ (Clinical research ed) 2009, 339:b2535.

32. Lymphogranuloma venereum (LGV) in Canada: Recommendations for Diagnosis and Treatment and Protocol for National Enhanced Surveillance. [http://www.phac-aspc.gc.ca/publicat/lgv/lgv-rdt-eng.php].

33. Lymphogranuloma Venereum Surveillance - STD information from CDC. [http://www.cdc.gov/std/lgv/stdfact-lgv.htm].

34. HPA - Guidelines. [http://www.hpa.org.uk/webw/ HPAweb\&Page\&HPAwebAutoListDate/Page/1191942171553?p = 1191942171553].

35. Management of LGV [2006]. [http://www.bashh.org/guidelines].
36. Elgalib A, White JA: Observed changes in CD4 count and HIV viral load during lymphogranuloma venereum (LGV) proctitis and non-LGV rectal Chlamydia trachomatis infection among HIV-positive men who have sex with men. Int J STD \& AIDS 2007, 18(Supplement 1):26-27, P68.

37. Lymphogranuloma venereum proctitis in Edinburgh, HPS Weekly Report 2005 [http://www.documents.hps.scot.nhs.uk/ewr/pdf2005/0506.pdf].

38. Samarawickrama A, Nambiar K, Collins I, Reeves I, Gillian D: Diagnostic utility of rectal microscopy in predicting lymphogranuloma venereum (LGV) in men who have sex with men (MSM): a case control study Abstract. Sex Transm Inf 2008, 84, e1.P78.B-09.

39. Annan N, Nori A, Naydenova P, McKenna A, Hawkins D, Azadian B, Ison C, Ward H, Sullivan A: Lymphogranuloma venereum (LGV): Clinical Presentation And Treatment Outcomes - Abstract. Sex Transm Inf 2008, 84, e1.P78.B-03.

40. Clark J, Espinosa B, Segundo L, Hall E, Salvatierra H, Caceres C, Klausner J, Coates T: Abscence of Lymphogranuloma Venereum Infection among High-Risk Men Who Have Sex with Men in Lima, Peru - Abstract. Sex Transm Inf 2008, 84, e1.P78.H-01.

41. Saunders P, Ali T, Alexander S, Ison C: Genotyping of Lymphogranuloma venereum LGV in United Kingdom - Abstract. Sex Transm Inf 2008, 84, e1. P78. 0-22.

42. Waalboer $\mathrm{R}$, van der Snoek EM, van der Meijden WI, Mulder PGH, Ossewaarde JM: Analysis of rectal Chlamydia trachomatis serovar distribution including L2 (lymphogranuloma venereum) at the Erasmus MC STI clinic, Rotterdam. Sex Transm Inf 2006, 82(3):207-211.

43. Spaargaren J, Schachter J, Moncada J, de Vries HJC, Fennema HSA, Pena AS, Coutinho RA, Morre SA: Slow epidemic of lymphogranuloma venereum L2b strain. Emerg Infect Dis 2005, 11(11):1787-1788.

44. Herida M, Sednaoui P, Couturier E, Neau D, Clerc M, Scieux C, Kreplak G, Goulet V, Hamers FF, de Barbeyrac B: Rectal lymphogranuloma venereum, France. Emerg Infect Dis 2005, 11(3):505-506.

45. Halioua B, Bohbot JM, Monfort L, Nassar N, de Barbeyrac B, Monsonego J, Sednaoui P: Ano-rectal lymphogranuloma venereum: 22 cases reported in a sexually transmited infections center in Paris. Eur J Dermatol 2006, 16(2):177-180.

46. Spaargaren J, Fennema HSA, Morre SA, de Vries HJC, Coutinho RA: New lymphogranuloma venereum Chlamydia trachomatis variant, Amsterdam. Emerg Infect Dis 2005, 11(7):1090-1092.

47. Herida M, de Barbeyrac B, Sednaoui P, Scieux C, Lemarchand N, Kreplak G, Clerc M, Timsit J, Goulet V, Desenclos JC, et al: Rectal lymphogranuloma venereum surveillance in France 2004-2005. Euro Surveill 2006, 11(9):155-156.

48. Pathela P, Blank S, Schillinger JA: Lymphogranuloma venereum: old pathogen, new story. Curr Infect Dis Rep 2007, 9(2):143-150.

49. van de Laar MJW, Koedijk FDH, Gotz HM, de Vries HJC: A slow epidemic of LGV in the Netherlands in 2004 and 2005. Euro Surveill 2006, 11(9):150-152.

50. Dougan S, Evans BG, Elford J: Sexually transmitted infections in Western Europe among HIV-positive men who have sex with men. Sex Transm Dis 2007, 34(10):783-790

51. Martin-Iguacel R, Llibre JM, Nielsen H, Heras E, Matas L, Lugo R, Clotet B, Sirera G: Lymphogranuloma venereum proctocolitis: a silent endemic disease in men who have sex with men in industrialised countries. Eur $J$ Clin Microbiol Infect Dis 2010, 29(8):917-925.

52. Timen A, Hulscher MEJL, Vos D, van de Laar MJW, Fenton KA, van Steenbergen JE, van der Meer JWM, Grol RPTM: Control measures used during lymphogranuloma venereum outbreak, Europe. Emerg Infect Dis 2008, 14(4):573-578.

53. Fenton KA, Imrie J: Increasing rates of sexually transmitted diseases in homosexual men in Western europe and the United States: why? Infect Dis Clin North Am 2005, 19(2):311-331.

54. Ng SC, Gazzard B: Advances in sexually transmitted infections of the gastrointestinal tract. Nat Rev Gastroenterol Hepatol 2009, 6(10):592-607.

55. Moodley P, Sturm PDJ, Vanmali T, Wilkinson D, Connolly C, Sturm AW: Association between HIV-1 infection, the etiology of genital ulcer disease, and response to syndromic management. Sex Transm Dis 2003, 30(3):241-245.

56. Bauwens JE, Orlander H, Gomez MP, Lampe M, Morse S, Stamm WE, Cone R, Ashley R, Swenson P, Holmes KK: Epidemic Lymphogranuloma venereum during epidemics of crack cocaine use and HIV infection in the Bahamas. Sex Transm Dis 2002, 29(5):253-259. 
57. Hamill M, Benn P, Carder C, Copas A, Ward H, Ison C, French P: The clinical manifestations of anorectal infection with lymphogranuloma venereum (LGV) versus non-LGV strains of Chlamydia trachomatis: a case-control study in homosexual men. Int J STD \& AIDS 2007, 18(7):472-475.

58. van der Snoek EM, Ossewaarde JM, van der Meijden WI, Mulder PGH, Thio HB: The use of serological titres of $\lg A$ and $\lg G$ in (early) discrimination between rectal infection with non-lymphogranuloma venereum and lymphogranuloma venereum serovars of Chlamydia trachomatis. Sex Transm Inf 2007, 83(4):330-334.

59. McConnell JJ, Bragg L, Shiboski S, Grant RM: Sexual seroadaptation: lessons for prevention and sex research from a cohort of HIV-positive men who have sex with men. PLOS ONE 2010, 5(1):e8831.

60. Velicko I, Cullberg M, Bratt G, Mamlov G, Johnsson A, Hansson HB, Herrmann B, Blaxhult A: [Lymphogranuloma venereum-increased spread in Sweden. A rare Chlamydia subtype which become more and more common among men who have sex with men]. Lakartidningen 2009, 106(1-2):28-31.

61. Stary G, Meyer T, Bangert C, Kohrgruber N, Gmeinhart B, Kirnbauer R, Jantschitsch C, Rieger A, Stary A, Geusau A: New Chlamydia trachomatis L2 strains identified in a recent outbreak of lymphogranuloma venereum in Vienna, Austria. Sex Transm Dis 2008, 35(4):377-382

62. Cusini M, Boneschi V, Arancio L, Ramoni S, Venegoni L, Gaiani F, de Vries H: Lymphogranuloma Venereum: the Italian experience. Sex Transm Inf 2008.

63. Vall Mayans M, Caballero E, Garcia de Olalla P, Armengol P, Codina MG, Barbera MJ, Sanz B, Andreu A, Cayla JA: Outbreak of lymphogranuloma venereum among men who have sex with men in Barcelona 2007/08an opportunity to debate sexual health at the EuroGames 2008. Euro surveill 2008, 13(25):18908.

64. Stark D, van Hal S, Hillman R, Harkness J, Marriott D: Lymphogranuloma venereum in Australia: anorectal Chlamydia trachomatis serovar L2b in men who have sex with men. J Clin Microbiol 2007, 45(3):1029-1031.

65. Bremer V, Meyer T, Marcus U, Hamouda O: Lymphogranuloma venereum emerging in men who have sex with men in Germany. Euro Surveill 2006 11(9):152-154

66. Gebhardt M, Goldenberger D: Lymphogranuloma venereum (LGV) serotype L2 in Switzerland, 2003-2005. Euro Surveill 2005, 10(12), E051222.051224.

67. de Vries HJC, van der Bij AK, Fennema JSA, Smit C, de Wolf F, Prins M, Coutinho RA, Morre SA: Lymphogranuloma venereum proctitis in men who have sex with men is associated with anal enema use and high-risk behavior. Sex Transm Dis 2008, 35(2):203-208.

\section{Pre-publication history}

The pre-publication history for this paper can be accessed here: http://www.biomedcentral.com/1471-2334/11/70/prepub

doi:10.1186/1471-2334-11-70

Cite this article as: Rönn and Ward: The association between Lymphogranuloma venereum and HIV among men who have sex with men: systematic review and meta-analysis. BMC Infectious Diseases 2011 $11: 70$.

\section{Submit your next manuscript to BioMed Central and take full advantage of:}

- Convenient online submission

- Thorough peer review

- No space constraints or color figure charges

- Immediate publication on acceptance

- Inclusion in PubMed, CAS, Scopus and Google Scholar

- Research which is freely available for redistribution 